\title{
Opportunistic Networks: Current Scenario and Future Scope
}

\author{
Amita Dev, Rahul Sachdeva
}

\begin{abstract}
Opportunistic Networks are considered as a subclass of Mobile Adhoc Networks in which packet can be delivered with a reasonable amount of delay. Initial Node or source node allows distinct nodes to join the network to accomplish message delivery. Opportunistic Networks follow the Store-Carry-Forward principle in order to deliver the packet. The intermediate node stores the packet in memory unless a suitable forwarder node is selected. Further Opportunistic Network imposes various challenges like maintain routes, energy optimization for mobile devices, congestion control, or buffer storage policies and security and privacy in the network. Various tools/simulators are available to simulate Opportunistic Networks protocols and analyze their results. The aim of this paper is to provide overview of Opportunistic Networks and major routing protocols available. Also this paper discusses applications of these kinds of networks and future scope of Opportunistic Network. Opportunistic Networks is an open-ended topic for researchers and imposes great challenges for future work. In future routing protocols can be optimized for lowering overhead and delay in the network, thus providing efficient environment for communication.
\end{abstract}

Keywords: MANETs, Network, ONE Simulator OppNets, Opportunistic

\section{INTRODUCTION}

$\mathrm{W}_{\mathrm{i}}$ ith extensive research performed in wireless technologies, communications becoming much faster, reliable and secure than before. With advancements in communication technologies, communication is even possible in geographical areas, which once imposes a major challenge. Wired Network imposes much infrastructure cost on initial setup, thus may not be feasible at every location. Traditional wireless networks such as mesh networks or mobile adhoc networks suffer due to disconnections. To overcome the challenges proposed by traditional wireless networks and eliminating high infrastructure costs, a new model is proposed as Opportunistic Networks (OppNets)[1].

Opportunistic Networks is a special sub-category of Mobile Adhoc Networks (MANETs) [2] and Delay Tolerant Networks (DTNs) in which messages can be delivered with the permissible amount of Delay. In DTNs, for data transmission from source to destination, an end to end path is requested first and in case of no such path between source node and destination node data is forwarded opportunistically. Whereas in OppNets, data is always

Revised Manuscript Received on October31, 2019

* Correspondence Author

Amita Dev, Vice-Chancellor, Indira Gandhi Delhi Technical University for Women, Kashmeri Gate, Delhi, India Email: amita_dev@ hotmail.com

Rahul Sachdeva*, Ph.D. Research Scholar, University School of Information and Communication and Technology, GGSIPU, New Delhi, India. Email: rahulsachdeva9333@gmail.com

forwarded opportunistic manner. MANETs on the other hand, participating devices are well aware of the network topology and data transferred is failed in case of any link breakage in established route. Whereas in OppNets, nodes are aware of only neighboring nodes and can store data in case of node path exists between the source and destination node.

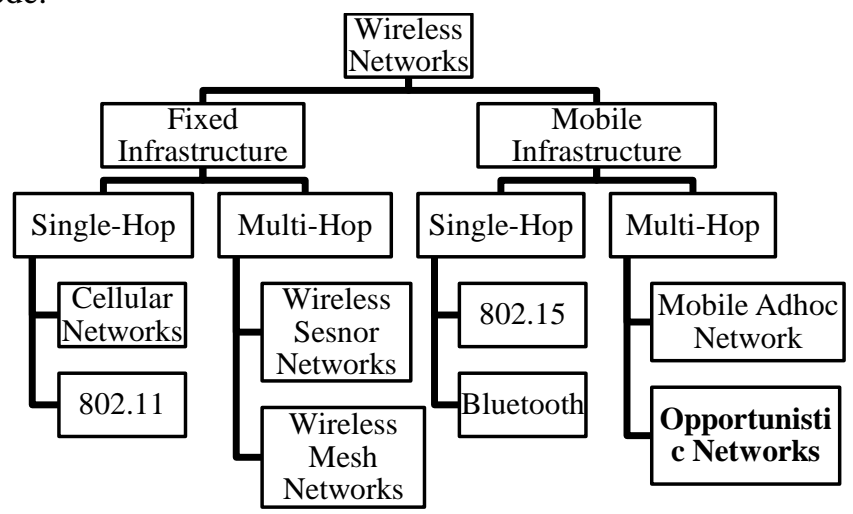

Fig. 1.Wireless Networks Hierarchy based upon Infrastructure Requirement

Figure 2 explains the basic concept behind message transmission in OppNets. Any mobile node, moving in the direction of destination with communication capabilities can be part of the network. The message started from the source is opportunistically forwarded to the next node with probability of bringing message nearer to the destination. In same manner next node is selected till message reaches its destination

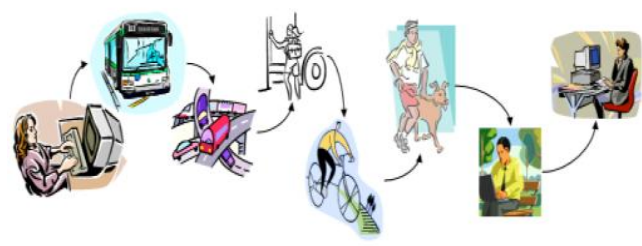

Fig. 2.Opportunistic Networks Concept

The paper is structured as follows. Section 2 describes Opportunistic Networks and its architecture. Section 3 discusses different categories of routing protocols for OppNets and various challenges faced in routing messages. Section 4 gives a brief about simulators available for implementing OppNets. Section 5 discusses applications and the future scope of OppNets. Section 6 concluded the paper. Section 7 gives references for work. 


\section{Opportunistic Networks: Current Scenario and Future Scope}

\section{OPPORTUNISTIC NETWORK}

Opportunistic Networks can be explained as a special category of Mobile Adhoc Networks with unstable topology, unpredictable disruptions \& link breakage. OppNets seeks the help of the neighboring nodes and networks to accomplish the task of data forwarding from source to destination. It allows nodes from adjoining networks to join dynamically to extend the network and perform routing. In case of no forwarding node, message is stored in the memory of node carrying the data until suitable node is identified to forward the message. In OppNets, following three things are important:

- Contact Opportunity: due to induces mobility of the nodes

- Storage Limitation: Mobile nodes in OppNets have limited storage with them

- Cooperation Level: Cooperation from nodes to participate and forward packet

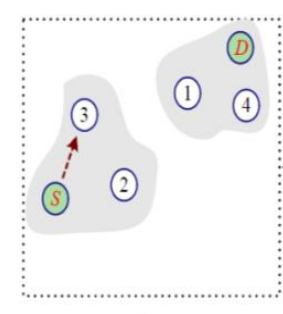

$t_{1}$

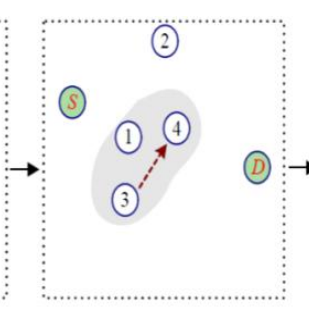

$t_{2}$

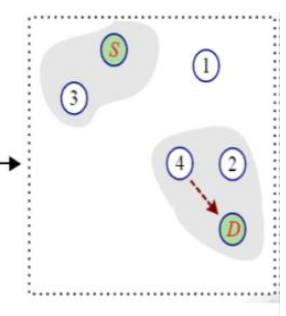

$t_{3}$
Fig. 3.Mobility Induced Network Formation

\section{A. Building Blocks of OppNets and Architecture}

OppNets distinguish themselves from traditional wireless networks in the manner they grow and communicate between source and destination nodes. There is no fixed location for the seed node (initial nodes in the network) or any prefixed topology or network size. In some cases, a seed node can be the only node initiating the network. These seed nodes allow foreign nodes to admit into the network and make expanded OppNet. These nodes can be of different categories. In OppNets, multiple regions can be formed from the expanded network and inter-region communication can be performed in similar store-carry-forward manner. This mechanism is implemented with help of extra layer for OppNets - "Bundle Layer". Following figures compare architectures of OppNets and TCP/IP[3].

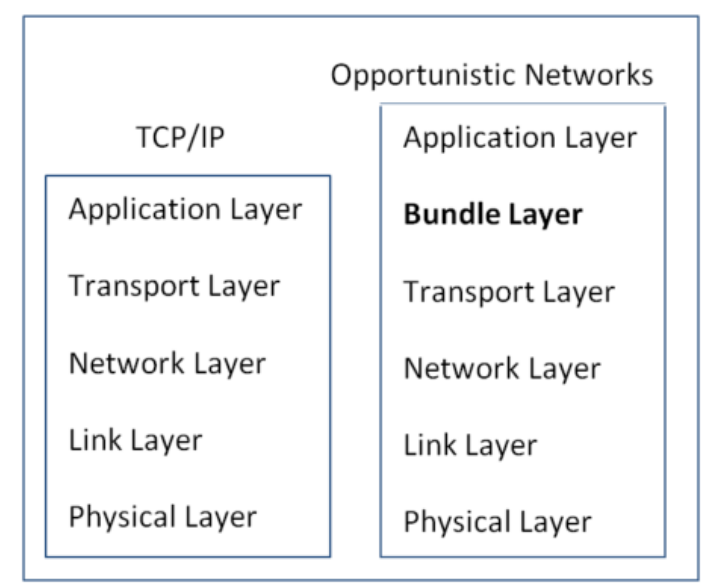

Fig. 4.TCP/IP VS. OppNets Layered Architecture

\section{ROUTING IN OPPORTUNISTIC NETWORK}

Routing can be explained as process of transmitting data packets from one node to another in the network with the help of intermediate nodes if required. Routing in OppNets depends upon:

- Contact Opportunity

- Node's Willingness

- $\quad$ Store-Carry-Forward Mechanism

The node carrying data packet may select any available node as a forwarder, which likely to bring packet closer to the destination or directly to the destination. In case of non-availability of any intermediate node, node carrying the message can store the packet in its storage till the time it finds suitable node that can bring packet nearer to the destination.

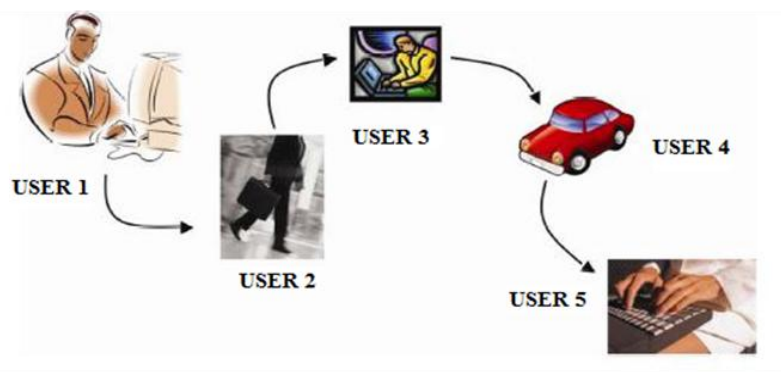

Fig. 5.Message Delivery in Opportunistic Networks

In the above scenario, User 1 wants to deliver a message to User 5 in some other location. User 1 will pass the message to User 2 via any communication link say Wi-Fi. User 2 crosses a train moving in direction towards the destination, may opportunistically forward the packet to node participating there to bring packet closer to the destination. User 3 in train can opportunistically pass message to User 4 in the car with the hope of bringing it further closer to the destination. In final step, User 4 itself delivers the packet to the destination node, i.e. user 5 .

\section{Characteristics of Routing in OppNets:}

- OppNets can be defined as a special case of MANETs and a sub-class of DTNs.

- OppNets follows the Store-Carry-Forward mechanism to deliver packets.

- Seed Node(s) allows foreign nodes (of diverse capabilities) to join the network and participate in routing of messages.

- Routing is entirely dependent on the mobility of the nodes. Thus disconnection can be there, but messages are stored in the memory of nodes carrying the packet till forwarder node is identified.

- Nodes in OppNets are aware of only local knowledge only, i.e., they have routing information about their neighbors only.

\section{A. Routing Protocols for OppNets}

Routing in OppNets can be categorized based on their need for infrastructure [4]. Protocols can further be sub-divided based upon their routing principles into different categories. 
A quick overview is given below for reference.

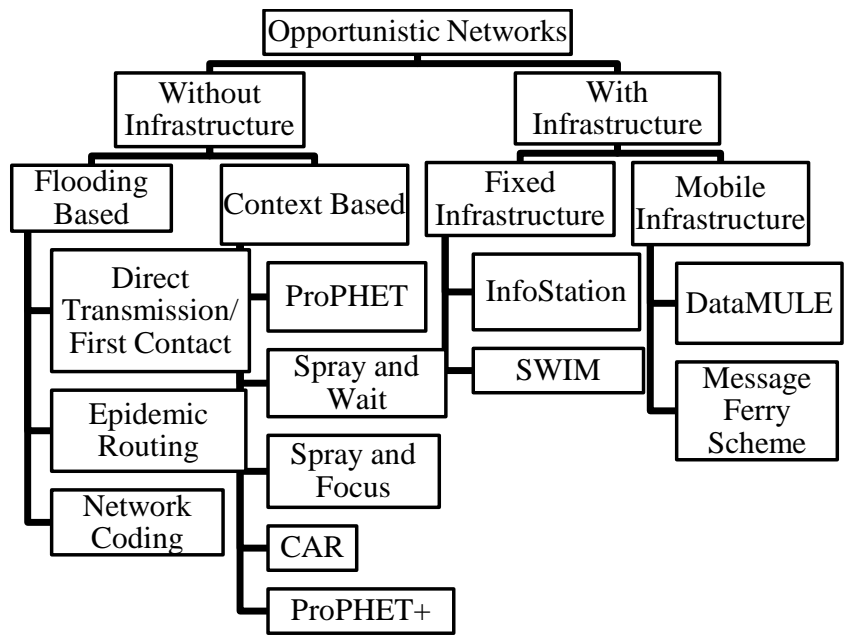

Fig. 6.Hierarchy for Routing Protocols for Opportunistic Networks

\section{- Flooding Based Routing Protocols}

Routing in OppNets mainly relies on the mobility of the participating nodes. One of the basic approach is to deliver packet in Oppnets is to forward packet to every other node in the network to increase the chances of delivering it to the destination node. Flooding based protocols make multiple copies of the packet and forward it to all the neighbors. Neighbors again forward it to all their adjacent nodes until packet reaches its destination.

Direct Delivery stores the packet until it comes in direct range of the destination and transmits packets directly to the destination. In First Contact forwards forward the packet to first node encountered. Epidemic Routing floods multiple copies of the packet in the network. Epidemic Routing uses uncontrolled flooding and there is no limit on the number of packets being flooded in the network.

\section{- Context-Based Routing Protocols}

Routing in Oppnets can be enhanced further with optimizing routing protocols with context information such as batter power remaining, previous encounter history, bandwidth, available buffer storage, etc. Many routing protocols are discussed in Table 1.

\section{- Fixed Infrastructure Based Routing Protocols}

In this category, some fixed infrastructure is required by OppNets to forward messages opportunistically. Infrastructure can be fixed or mobile depending upon the need and forwarding algorithm. In both cases, infrastructure used is robust in terms of storage and energy levels.

In Infrastructure based routing, the base station is usually used as a relay agent or gateways to deliver messages to the destination node. Source node stores the data packet unless it comes in a range of suitable base station, which can further relay message to destination network more efficiently. For fixed infrastructure there are mainly two routing approached which are used:

i. InfoStation Model [5]: Communication in done between mobile nodes and fixed base stations known as InfoStations. InfoStations are always connected and are capable of high bandwidth services. It acts as Gateways and node wanting to transmit data need to the node to InfoStation range and upload the data. Then InfoStation is responsible for the delivery of the data to the destination node. The delivery delay is usually very high in such scenario.

ii. Shared Wireless InfoStation Model (SWIM) [6]: It can be explained as an extended model for InfoStations by allowing multihop data in place of the node to base station communication only. The node which wants to participate in communication and want to deliver message can either send message directly to InfoStation if in transmission range or can forward to other nodes in network opportunistically which can further forward to the InfoStation. As per simulation results it shows decrease in transmission delays but with cost if high transmission bandwidth and buffer storage.

\section{- Mobile Infrastructure Based Routing Protocols}

Infrastructure nodes act as Mobile Data Collectors and move around in the network on either predetermined fixed path or completely random path to collect messages from the nodes within their data range. These unique nodes in the network are known as Carriers, Forwarders, Mobile Ubiquitous LAN Extensions (MULEs), or even ferries. Following are examples of such routing algorithms:

i. Data-MULE [7]: It is a 3 tier approach with the aim of data collection/retrieval in sparse Wireless Sensor Network (WSN).

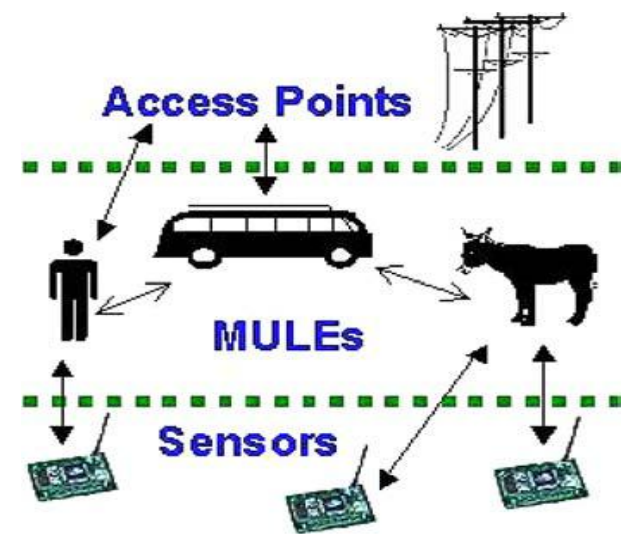

Fig. 7.Architecture for Data-MULE

1st Tier or lower tier consists of the sensor nodes responsible for sensing and collecting data samples periodically. The 2nd layer comprises of MULEs or mobile agent responsible for data collection from the sensors. MULEs are allowed to move freely in the network. The top tier is mainly Data repositories or Wired Access Points collecting information from the MULEs. Data Repositories can be further connected with Data Warehouse for data storage and processing.

ii. Message Ferrying Approach [8]: It is mobility induced approach, in which additional wireless mobile devices (known as Ferries or Message Ferries) are introduced to act as a message relay agent. Message Ferries roam in the network freely and can collect data packets from nodes in following ways: 
Table 1: Infrastructure-less Routing Algorithms for Opportunistic Networks

\begin{tabular}{|c|c|c|c|c|c|c|}
\hline \multirow[b]{2}{*}{$\begin{array}{l}\text { Routing } \\
\text { Protocol }\end{array}$} & \multirow[b]{2}{*}{ Routing Principle } & \multirow{2}{*}{$\begin{array}{l}\text { Assumptions } \\
\text { Made(if any) }\end{array}$} & \multicolumn{2}{|c|}{ Algorithm } & \multirow[b]{2}{*}{$\begin{array}{l}\text { Remarks/ } \\
\text { Drawback }\end{array}$} & \multirow{2}{*}{$\begin{array}{l}\text { Simulator } \\
\text { Used }\end{array}$} \\
\hline & & & $\begin{array}{l}\text { Copies of } \\
\text { Messages }\end{array}$ & $\begin{array}{c}\text { Selection of } \\
\text { Next Hop }\end{array}$ & & \\
\hline $\begin{array}{c}\text { Direct Delivery } \\
\text { [9] }\end{array}$ & $\begin{array}{l}\text { Message is stored in } \\
\text { memory until comes in } \\
\text { direct transmission range of } \\
\text { the destination node for } \\
\text { delivery. }\end{array}$ & $\begin{array}{l}\text { Limited Memory } \\
\text { Buffer Size }\end{array}$ & Single & $\begin{array}{l}\text { Destination } \\
\text { Node }\end{array}$ & $\begin{array}{lr}\text { High } & \text { transmission } \\
\text { Delays } & \text { due to } \\
\text { undefined } & \text { network } \\
\text { topology } & \end{array}$ & $\begin{array}{l}\text { Custom } \\
\text { Java-Based } \\
\text { Discrete } \\
\text { Event-Driven }\end{array}$ \\
\hline $\begin{array}{c}\text { First Contact } \\
{[10]}\end{array}$ & $\begin{array}{l}\text { Forwards the packet to next } \\
\text { available node in the contact }\end{array}$ & Not Mentioned & Single & $\begin{array}{l}\text { Next node in } \\
\text { range }\end{array}$ & $\begin{array}{l}\text { High delay and } \\
\text { Looping Problem }\end{array}$ & $\begin{array}{l}\text { Own DTN } \\
\text { Simulator }\end{array}$ \\
\hline $\begin{array}{c}\text { Epidemic } \\
{[11]}\end{array}$ & $\begin{array}{l}\text { Make unlimited copies of } \\
\text { the packet and node carrying } \\
\text { packet forward to all other } \\
\text { nodes in the transmission } \\
\text { range. }\end{array}$ & $\begin{array}{l}\text { Limited Memory } \\
\text { Buffer Size }\end{array}$ & Unlimited & Flooding & $\begin{array}{ll}\text { High } & \text { resource } \\
\text { utilization } & \end{array}$ & Monarch \\
\hline $\begin{array}{c}\text { Network } \\
\text { Coding } \\
{[12]}\end{array}$ & $\begin{array}{l}\text { The network coding } \\
\text { principle can be applied to } \\
\text { Epidemic Routing Protocol } \\
\text { for considering routing } \\
\text { paths rather than replicating } \\
\text { packets in the network. } \\
\text { Coding is performed at } \\
\text { intermediate nodes to } \\
\text { optimize the performance. }\end{array}$ & $\begin{array}{l}\text { Sufficient } \\
\text { Memory Buffer } \\
\text { available }\end{array}$ & Limited & Flooding & $\begin{array}{l}\text { Packets forwarded are } \\
\text { encoded and } \\
\text { destination node needs } \\
\text { to wait till receives all } \\
\text { the packets to perform } \\
\text { decoding }\end{array}$ & $\begin{array}{l}\text { Custom } \\
\text { Java-Based } \\
\text { Discrete } \\
\text { Event-Driven }\end{array}$ \\
\hline $\begin{array}{c}\text { ProPHET } \\
\text { [13] }\end{array}$ & $\begin{array}{l}\text { The next node is selected } \\
\text { based upon the probability } \\
\text { values obtained from } \\
\text { previous encounters. }\end{array}$ & $\begin{array}{l}\text { Limited Memory } \\
\text { Buffer Size }\end{array}$ & Single & $\begin{array}{l}\text { Probability } \\
\text { Obtained from } \\
\text { previous } \\
\text { encounters }\end{array}$ & $\begin{array}{l}\text { Overhead calculation } \\
\text { at each node }\end{array}$ & $\begin{array}{l}\text { Own } \\
\text { Simulator }\end{array}$ \\
\hline $\begin{array}{l}\text { Spray and } \\
\text { Wait } \\
{[14]}\end{array}$ & $\begin{array}{l}\text { Algorithm mainly works in } \\
\text { two phases. In the spray } \\
\text { phase, limited numbers of } \\
\text { copies are forwarded to all } \\
\text { nodes present in the } \\
\text { network. In Wait phase, } \\
\text { each node wait for the } \\
\text { destination node to comes } \\
\text { directly in range for direct } \\
\text { transmission. }\end{array}$ & $\begin{array}{l}\text { Sufficient } \\
\text { Memory Buffer } \\
\text { available }\end{array}$ & Limited & Randomly & $\begin{array}{l}\text { Decision making is } \\
\text { Random }\end{array}$ & $\begin{array}{l}\text { Own } \\
\text { Simulator }\end{array}$ \\
\hline $\begin{array}{l}\text { Spray and } \\
\text { Focus } \\
{[15]}\end{array}$ & $\begin{array}{l}\text { Tokens are generated and } \\
\text { forwarded along with a copy } \\
\text { of the messages. Nodes } \\
\text { having tokens can only } \\
\text { produce a copy of the } \\
\text { message and forward. Rest } \\
\text { wait for direct transmission. }\end{array}$ & $\begin{array}{l}\text { Sufficient Buffer } \\
\text { available }\end{array}$ & Limited & $\begin{array}{l}\text { Timer Based } \\
\text { Flooding }\end{array}$ & $\begin{array}{l}\text { High resource } \\
\text { consumption }\end{array}$ & $\begin{array}{l}\text { Own } \\
\text { Simulator }\end{array}$ \\
\hline $\begin{array}{l}\text { CAR } \\
{[16]}\end{array}$ & $\begin{array}{l}\text { Various Parameters such as } \\
\text { Energy Level, mobility of } \\
\text { the node, and other } \\
\text { contextual information is } \\
\text { used to predict delivery } \\
\text { probability using Utility } \\
\text { Theory along with Kalman } \\
\text { Filter Based Prediction } \\
\text { techniques }\end{array}$ & $\begin{array}{l}\text { Sufficient } \\
\text { Memory Buffer } \\
\text { available }\end{array}$ & Single & $\begin{array}{l}\text { Utility Theory } \\
\text { along with } \\
\text { Kalman Filter } \\
\text { Based } \\
\text { Prediction } \\
\text { techniques }\end{array}$ & $\begin{array}{l}\text { No previous } \\
\text { knowledge is used to } \\
\text { make the routing } \\
\text { decision. Routes are } \\
\text { re-generated every } \\
\text { time as and when } \\
\text { require. }\end{array}$ & OMNET++ \\
\hline $\begin{array}{c}\text { ProPHET+ } \\
{[17]}\end{array}$ & $\begin{array}{l}\text { Probability obtained from } \\
\text { the previous meeting is } \\
\text { further optimized by } \\
\text { considering buffer storage, } \\
\text { energy available, } \\
\text { bandwidth, etc. }\end{array}$ & $\begin{array}{l}\text { Sufficient } \\
\text { Memory Buffer } \\
\text { available }\end{array}$ & Single & $\begin{array}{l}\text { Node with } \\
\text { highest } \\
\text { delivery } \\
\text { probability is } \\
\text { selected from } \\
\text { available set }\end{array}$ & $\begin{array}{lr}\text { Weighted factors } & \text { are } \\
\text { determined } & \text { for } \\
\text { calculating } & \text { delivery } \\
\text { probability can be } \\
\text { overhead in the } \\
\text { network. }\end{array}$ & $\begin{array}{l}\text { NS-2/DTNSI } \\
\mathrm{M}\end{array}$ \\
\hline
\end{tabular}




\begin{tabular}{|c|l|l|l|l|l|}
\hline & $\begin{array}{l}\text { Each node is required to } \\
\text { maintain Identity tables } \\
\text { HiBOp }\end{array}$ & which stores routing \\
[18] & $\begin{array}{l}\text { Managed and } \\
\text { information based upon } \\
\text { history encounters that are } \\
\text { used for routing decisions. }\end{array}$ & $\begin{array}{l}\text { Limited Memory } \\
\text { Buffer Size }\end{array}$ & Single & $\begin{array}{l}\text { Tables are } \\
\text { used to } \\
\text { identify the } \\
\text { next possible } \\
\text { node }\end{array}$ & $\begin{array}{l}\text { Maintaining Identity } \\
\text { table for the network } \\
\text { is overhead }\end{array}$ \\
\hline
\end{tabular}

a. Node Initiated Message Ferrying (NIMF): In this approach, ferry node moves in the predefined path and nodes participating in the network are el aware of the path defined for Ferry node. Any node wants to communicate in the network moves towards active ferry node and delivers the message.

b. Ferry Initiated Message Ferrying (FIMF): In this However, the node which wants to communicate has to send Service Request (via Radio Signal) to Ferry node along with its current position.

\section{B. Challenges in Routing in OppNets}

Due to the mobility induced and opportunistic approach, it imposes various challenges for routing in OppNets. One of the major challenge of OppNets is to establish and maintain path for data communication as no fixed path exists for communication between two nodes. Another challenge arises due to diverse nature of nodes in the OppNets. Most of the devices participating in OppNets are battery powered and can affect the overall lifetime of the network in case low energy. Also suspicious nodes can take advantage of flooding mechanism. So security and privacy is another concern in OppNets. Due to store-carry-forward paradigm of OppNets, Buffer Storage Management is another task to be taken care of. Major challenges are discussed below:

- Interoperability Problem: OppNets allows distinct devices like mobile phones, different sensors, handheld communication devices, etc. to join the network and form extended OppNet. These devices are different in terms of data communication capabilities, thus leads to an Interoperability problem.

- Energy Efficiency: OppNets uses mostly handheld devices capable of performing data communication. But these devices being part of OppNets require much amount of energy to perform the required task. Many routing algorithms are proposed to optimize energy levels in OppNets. Authors in [19] propose modified epidemic algorithm focused on energy level of the nodes. Only those nodes can forward the packets which have $\mathrm{n}$ minimum neighbors (defined threshold value). Also, authors have modified Spray and Wait routing protocol in [20] to improve routing efficiency.

- Buffer Storage Management: Routing in OppNets depends upon the Store-Carry-Forward approach to communicate in the network. This imposes much storage requirement on the nodes participating in the communication. In paper [21] authors have proposed congestion avoidance policy at node level. With every stored packet its lifetime is checked with threshold value set for dropping the packet. When value falls below the threshold packet can be dropped and storage can allocated to new packets. In another approach [22], if buffer storage if full, it can forward message to its neighbor node to act as custodian and can retrieve back when storage is available. approach ferry node nodes on the predefined as well.

- Data Integrity and Security: Data security is always a prime concern in data communication. Various protocols are proposed to ensure data integrity and security. In [23], the authors proposed a trust-based framework based on the trace-based mobility model. Next node selection is based upon the trust value and direction of the node.

- Malicious Nodes: The presence of malicious nodes can affect network performance. In [24], the authors introduced a new approach to judge node's behavior and check whether suitable for selecting as forwarder or not in order to provide secure medium. Third-party nodes not participating in communication are used as judge.

\section{IMPLEMENTING OPPNETS}

Traditional wireless networks require global information and fixed topology to perform data communication and can be simulated or modeled using conventional simulators. OppNets require discrete communication where there can be various disruptions in the communication and message can be transmitted with permissible amount of delay. Also support for mobility models required is inspired from real life. This kind of approach requires simulator to work as a real-life environment. Various simulators are upgraded to support such requirement. Some of them are discussed below:

- ONE Simulator [25]: ONE (Opportunistic Network Environment) Simulator works as a discrete event simulation engine designed especially for simulating OppNets. ONE is broken into multiple modules to perform different activities. Major responsibilities of ONE simulator include inter-node communication, analyzing the node's movement, routing, and packet handling. Reports are generated and analysis is done through Java-Based Visualizer and post-processing tools.

- OMNET++ [26]: It is $\mathrm{C}++$ based extensible, modular discrete event generator simulator for simulating communication protocols and networks. INET Framework in OMNET++ supports various IP Protocols for simulating OppNets. The functioning of OMNET++ is divided into two major modules:

- Active Module: Written using $\mathrm{C}++$, responsible for simulating class library

- Compound Module: Responsible to look after connections state for message delivery

- NS-3 [27]: Network Simulator 3 is discrete event generator open-source software that uses $\mathrm{C}++$ and Python languages to simulate scenarios. Concerning OppNets, NS-3 can simulate Mobility, Traffic Management, Data Propagation Protocols and Link Control, etc. It allows importing external libraries to extend support along with inbuilt libraries. Network Animator (NetAmin) is used for visualization purposes. 


\section{Opportunistic Networks: Current Scenario and Future Scope}

\section{APPLICATION AND FUTURE SCOPE OF OPPORTUNISTIC NETWORK}

Traditional Wireless Networks such as Wireless Sensor Networks or MANETs requires global knowledge of the network and does not support dynamic topology. Hence it becomes tough to maintain the network in case of frequent topology change. Further when compared with fixed wired networks it imposes high infrastructure cost which makes it less feasible in many situations.

This demands for the dynamic network which can support frequent disruptions and topology change, OppNets due to its store-carry-forward principle fits perfectly in the case. In case of frequent oath breaks it can store the information to find suitable forwarder node for the message. Few of the application of OppNets are discussed below:

\section{A. Wildlife Monitoring Networks}

One of the major applications of OppNets is wildlife monitoring systems. OppNets can be used to study mobility patterns, behavior, interaction and influence with others. These systems proved to be low cost, efficient and reliable approach for study and monitoring wildlife over vast areas or forest regions. Major projects undertaken are discussed below:

- Princeton University had implemented ZebraNet [28] in the vast region of Savanna (Central Kenya) to monitor wildlife. Powerful sensors functioning as P2P network are tied around neck of the Zebras to set up Wireless Mobile Sensor Network. It is designed to monitor movement traces of the Zebras.

- CenWits [29] (Connection-less Sensor-Based Tracking System Using Witnesses) is designed for smart search or rescue in case of emergencies in remote areas where sensors attached to the person can transmit exact location of the person through Access Points.

- Shared Wireless InfoStation Model [30] is a similar model based upon OppNets as of ZebraNet to study the behavior and movement of blue Whale's species.

\section{B. Underwater Sensor Network (UWSN)}

UWSN [31] opens a new level of opportunities to explore for researchers to study and understand coral reef and other aquatic life along with various environmental issues arising like climate change, etc. It uses TDMA protocol communication. Sensors are deployed underwater and the robot is implemented, which roam around underwater and collects data from sensors within the range.

\section{Emergency Response Systems}

OppNets can start with a single seed node and grows into expanded networks by admitting foreign distinct nodes. Taking advantage of this property in case of emergencies, instantaneous networks can be deployed to communicate and broadcast recuse information.

OppNets are open-ended topics for researchers to study with various challenges and applications. Various sensor networks are being deployed taking advantage of opportunistic communication of the OppNets. On research prospective, routing protocols can be designed to mitigate challenges faced in Opportunistic Networks viz. route optimization for better throughput or reduced time delay, device battery power management (better energy consumption policies), congestion management policies.

\section{Internet Access to Rural Areas}

OppNets can be feasible economically and technically to deploy in the region with less population and high infrastructure costs for traditional networks. DakNet [32] developed by the researcher of MIT Media Lab and deployed in specific regions in India and Cambodia is live example. Kiosks are set up in remote locations that are having data communication capabilities and Mobile Access Points are installed on the top of on buses, etc. to enable data communication.

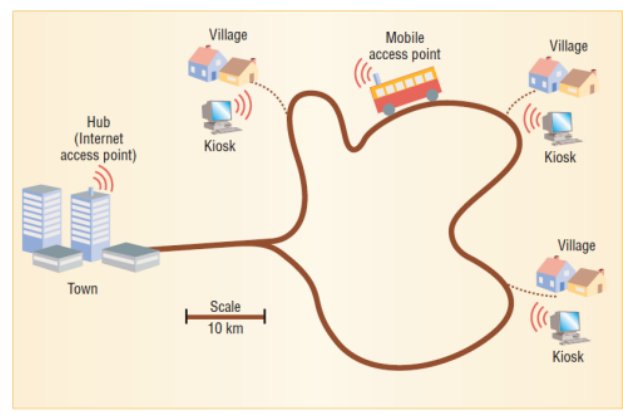

Fig. 8.DakNet Concept

\section{CONCLUSION}

The motive of the paper is to serve as elementary material for researchers who are keen in Opportunistic Networks. OppNets are fast growing due to its various applications in real life and store-carry-forward approach, which make it feasible in disruptions conditions as well. Various routing protocols are proposed for OppNets mainly focused on an infrastructure-less operation to take full advantage of its properties. Prediction based routing algorithms can be prime focus to work upon to further enhance delivery probabilities and to reduce network overhead of extra calculations.

\section{REFERENCES}

1. Trifunovic, S., Kouyoumdjieva, S. T., Distl, B., Pajevic, L., Karlsson, G., \& Plattner, B. (2017). A Decade of Research in Opportunistic Networks: Challenges, Relevance, and Future Directions. IEEE Communications Magazine, 55(1), 168-173. doi:10.1109/mcom.2017.1500527 cm

2. Abusalah, L., Khokhar, A., \& Guizani, M. (2008). A survey of secure mobile Ad Hoc routing protocols. IEEE Communications Surveys \& Tutorials, 10(4), 78-93. Quarter Four 2018 doi:10.1109/surv.2008.080407

3. Huang, C. M., Lan, K., \& Tsai, C.-Z. (2008). A Survey of Opportunistic Networks. 22nd International Conference on Advanced Information Networking and Applications - Workshops (AINA Workshops, 2008). doi:10.1109/waina.2008.292

4. Abdelkader, T., Naik, K., Nayak, A., Goel, N., \& Srivastava, V. (2016). A performance comparison of delay-tolerant network routing protocols. IEEE Network, 30(2), 46-53. doi:10.1109/mnet.2016.7437024

5. David J. Goodman, Joan Borras, Narayan B. Mandayam and Roy D Yates, "INFOSTATIONS: A New System Model for Data and Messaging Services," IEEE Vehicular Technology Conference 1997( VTC'97), vol. 2, May 1997, pp. 969-973.

6. T. Small and Z. J. Haas, "The Shared Wireless Infostation Model - A New Ad Hoc Networking Paradigm (or Where There is a Whale, there is a Way)," Proc. 4th ACM Int'l. Symp. Mobile Ad Hoc Networking and Computing (MobiHoc 2003), Annapolis, MD, June 1-3, 2003. 
7. S. Jain, R. C. Shah, W.Bbrunette, G. Borriello and S. Roy, "Exploiting Mobility for Energy Efficient Data Collection in Wireless Sensor Networks," ACM/Kluwer Mobile Networks and Applications (MONET), vol. 11, no. 3, June 2006, pp. 327-339.

8. W. Zhao, M. Ammar, and E. Zegura, "A Message Ferrying Approach for Data Delivery in Sparse Mobile Ad Hoc Networks," in proceedings of 5th ACM Int'l. Symp. Mobile Ad Hoc Networking and Computing 2004 (MobiHoc '04), ACM Press, Tokyo, Japan, 24-26 May 2004, pp. 187-198.

9. Spyropoulos, T., Psounis, K., \& Raghavendra, C. S. (n.d.). Single-copy routing in intermittently connected mobile networks. 2004 Firs Annual IEEE Communications Society Conference on Sensor and Ad Hoc Communications and Networks, 2004. IEEE SECON 2004. doi:10.1109/sahen.2004.1381922

10. Jain, S., Fall, K., \& Patra, R. (2004). Routing in a delay tolerant network. Proceedings of the 2004 Conference on Applications, Technologies, Architectures, and Protocols for Computer Communications - SIGCOMM '04. doi:10.1145/1015467.1015484

11. Vahdat, A.; Becker, D. Epidemic Routing for Partially Connected Ad Hoc Netw. 2000. Technical Report CS 200006 2000, Department of Computer Science, Duke University, NC. Available online: http://citeseerx.ist.psu.edu/viewdoc/summary?doi=10.1.1.34.6151 (accessed on 25 Sept. 2019)

12. Lin, Y., Liang, B., \& Li, B. (2007). Performance modeling of network coding in epidemic routing. Proceedings of the 1st International MobiSys Workshop on Mobile Opportunistic Networking - MobiOpp '07. doi:10.1145/1247694.1247709

13. Lindgren, A., Doria, A., \& Schelén, O. (2003). Probabilistic routing in intermittently connected networks. ACM SIGMOBILE Mobile Computing and Communications Review, 7(3), 19 doi:10.1145/961268.961272

14. Spyropoulos, T., Psounis, K., \& Raghavendra, C. S. (2005). Spray and wait. Proceeding of the 2005 ACM SIGCOMM Workshop on Delay-Tolerant Networking - WDTN '05. doi:10.1145/1080139.1080143

15. Spyropoulos, T., Psounis, K., \& Raghavendra, C. S. (2007). Spray and Focus: Efficient Mobility-Assisted Routing for Heterogeneous and Correlated Mobility. Fifth Annual IEEE International Conference on Pervasive Computing and Communications Workshops (PerComW'07). doi:10.1109/percomw.2007.108

16. Musolesi, M., \& Mascolo, C. (2009). CAR: Context-Aware Adaptive Routing for Delay-Tolerant Mobile Networks. IEEE Transactions on Mobile Computing, 8(2), 246-260. doi:10.1109/tmc.2008.107

17. Huang, T.-K., Lee, C.-K., \& Chen, L.-J. (2010). PRoPHET+: An Adaptive PRoPHET-Based Routing Protocol for Opportunistic Network. 2010 24th IEEE International Conference on Advanced Information Networking and Applications. doi:10.1109/aina.2010.162

18. Boldrini, C., Conti, M., Jacopini, J., \& Passarella, A. (2007). HiBOp: a History Based Routing Protocol for Opportunistic Networks. 2007 IEEE International Symposium on a World of Wireless, Mobile and Multimedia Networks. doi:10.1109/wowmom.2007.4351716

19. Xiaofeng Lu, Pan Hui , "An Energy-Efficient n-Epidemic Routing Protocol for Delay Tolerant Networks", 2010 IEEE Fifth International Conference on Networking, Architecture, and Storage, Print ISBN: 978-1-4244-8133-0

20. Viren G. Patel, Tushar K. Oza, Dhavalsinh M. Gohil , "Vibrant Energy Aware Spray and Wait Routing in Delay Tolerant Network", Journal of Telematics and Informatics (JTI) Vol.1, No.1, March 2012, pp. 43 47 ,ISSN: 2303-3703

21. Bingting Wang, Yanjun Hu, Hui Liang, Qibin Lin, Yonghua Shi, Xianbing Wang, "Congestion Control Strategy Based on Probability Selection in Delay Tolerant Mobile Sensor Network", Journal of Information \& Computational Science, September 20, 2014, ISSN: 1548-7741, DOI: 10.12733/jics20103637

22. M. Seligman, K. Fall, and P. Mundur, "Storage Routing for DTN Congestion Control", Wireless Communications and Mobile Computing, Vol. 7, Issue. 10, Page(s) 1183-1196, 2007

23. B.Poonguzharselvi, V.Vetriselvi, "Trust Framework for Data Forwarding in Opportunistic Networks using Mobile Traces", International Journal of Wireless \& Mobile Networks (IJWMN), Vol. 4, No. 6, December 2012, DOI: 10.5121/ijwmn.2012.4609

24. Zhaoyu Gaoy, Haojin Zhuy, Suguo Duy, Chengxin Xiaoy and Rongxing Luz, "PMDS: A Probabilistic Misbehavior Detection Scheme in DTN", In Proceedings of International Conference on Communications (ICC), IEEE pp. 4970-4974, June 2012, Electronic ISBN: 978-1-4577-2053-6, Print ISBN: 978-1-4577-2052-9

25. Keränen, A., "Opportunistic Network Environment Simulator" Special Assignment report, Helsinki University of Technology, Department of Communications and Networking, May 2008.
26. Helgason, Ó. R., \& Jónsson, K. V. (2008, March). Opportunistic networking in OMNeT++. In Proceedings of the 1st international conference on Simulation tools and techniques for communications, networks and systems \& workshops (p. 82). ICST (Institute for Computer Sciences, Social-Informatics and Telecommunications Engineering)

27. Riley, G. F., \& Henderson, T. R. (2010). The ns-3 network simulator In Modeling and tools for network simulation (pp. 15-34). Springer Berlin, Heidelberg.

28. Martonosi, M. (2004). The Princeton ZebraNet Project: Sensor Networks for Wildlife Tracking. Princeton University, 2-7.

29. Huang, J. H., Amjad, S., \& Mishra, S. (2005, November). Cenwits: a sensor-based loosely coupled search and rescue system using witnesses. In Proceedings of the 3rd international conference on Embedded networked sensor systems (pp. 180-191). ACM.

30. Small, T., \& Haas, Z. J. (2003, June). The shared wireless infostation model: a new ad hoc networking paradigm (or where there is a whale, there is a way). In Proceedings of the 4th ACM international symposium on Mobile ad hoc networking \& computing (pp. 233-244). ACM.

31. Chandrasekhar, V., Seah, W. K., Choo, Y. S., \& Ee, H. V. (2006, September). Localization in underwater sensor networks: survey and challenges. In Proceedings of the 1st ACM international workshop on Underwater networks (pp. 33-40). ACM.

32. Pentland, A., Fletcher, R., \& Hasson, A. (2004). DakNet: rethinking connectivity in developing nations. Computer, 37(1), 78-83. doi: $10.1109 / \mathrm{mc} .2004 .1260729$

\section{AUTHORS PROFILE}

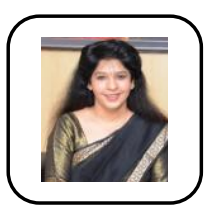

Dr. (Mrs.) Amita Dev is Vice-Chancellor of Indira Gandhi Delhi Technical University for Women. She received Ph.D. (Computer Engineering) from Delhi Technological University and MS from BITS, Pilani. She has excellent track record of Administration, Quality Teaching, Innovation and Research. Dr. Amita Dev has more than 33 years of experience in Industry, Teaching, Research and Administration. Her teaching and research areas include Artificial Neural Networks, Speech Processing, Opportunistic Networks, Speech Recognition Systems, MANETS, Advanced Computer Networks, and Data Mining etc. She has published $60+$ research papers in International and National Journals and Conference Proceedings. She is the recipient of AICTE Young Teacher Career Research Awardee, State Level Best Teacher Award, ISTE National Level Award for significant contributions in research.

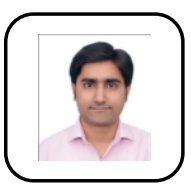

Rahul Sachdeva is pursing Ph.D. from USICT, Guru Gobind Singh Indraprastha University since 2016. He has completed his B.Tech and M.Tech in Information Technology. His research areas are routing in Adhoc Networks \& Opportunistic Networks. He has published various research articles in his domain. 